\title{
A first estimation of uncertainties related to microplastic sampling in
}

\section{rivers}

Antoine Bruge ${ }^{1^{*}}$, Marius Dhamelincourt ${ }^{1}$, Laurent Lanceleur ${ }^{2}$, Mathilde Monperrus ${ }^{2}$, Johnny

Gasperi $^{3,4}$, Bruno Tassin ${ }^{3}$

(1) Surfrider Foundation Europe, 33, allée du Moura, 64200 Biarritz, Pyrénées-Atlantiques, France.

(2) CNRS / UNIV PAU \& PAYS ADOUR / E2S UPPA, Institut des sciences analytiques et de physicochimie pour l'environnement et les matériaux - MIRA, UMR5254, 64600, ANGLET, France.

(3) LEESU (UMR MA 102), Université Paris-Est, Université Paris-Est Créteil, Ecole des Ponts ParisTech, 61 avenue du Général de Gaulle, 94010 Créteil Cedex, France.

(4) GERS-LEE, Université Gustave Eiffel, IFSTTAR, F-44344 Bouguenais, France.

*Corresponding author: abruge@surfrider.eu; Tel.: +33-559-235-499

\section{Abstract}

Many studies have been conducted to quantify microplastic contamination, but only a few of them have actually the sampling methodology and associated uncertainties. This study seeks to examine the influence of sampling strategy on the confidence interval of river microplastic estimates. 16 samples are collected in the Gave de Pau River (southwestern France) during a three-hour window with a 330- $\mu \mathrm{m}$ mesh size net. Three different exposure times $(3,5$ and 7 minutes) allow for a respective filtration rate by the net of $35.6 \mathrm{~m}^{3}$ (3 samples), $59.4 \mathrm{~m}^{3}$ (10 samples), and $83.2 \mathrm{~m}^{3}$ (3 samples) of water. Organic matter contained in samples is removed by hydrogen peroxide oxidation. The plastic particles are then counted and classified under a binocular microscope. The microplastic concentrations vary between 2.64 and 4.24 microplastics $/ \mathrm{m}^{3}$, with a median value of 3.26 microplastics $/ \mathrm{m}^{3}$. Statistical analysis does not show differences in microplastic concentrations for the three exposure times. This result 
seems to demonstrate that a filtration of approx. $35 \mathrm{~m}^{3}$ of water is sufficient under similar conditions (similar flow condition and degree of microplastic contamination) and can help reduce sampling and sample processing time. Other analyses, based on 10 filtrations of 59.4 $\mathrm{m}^{3}$, show that the higher the number of samples, the lower the confidence interval. For triplicates, the mean confidence interval reaches $15 \%$ of the median value. Thus, collecting triplicates would seem to offer a reasonable optimum, in combining an acceptable error percentage and time efficiency. These results might depend on the microplastic load of the river, therefore making it necessary to conduct similar analyses on other rivers. This study reports for the first time uncertainties related to microplastic sampling in rivers. Such findings will serve to set up long term monitoring, highlight spatial differences between sites and improve the accuracy of annual microplastic fluxes in rivers.

Keywords: microplastics, uncertainties, rivers, pollution, sampling methodology

\section{Introduction}

Over the last decade, considerable attention has been paid to plastic pollution in the marine environment (Li et al., 2018; Li et al., 2016). Yet rivers, which are one of the major pathways for plastics entering the ocean, have not been investigated to the same extent despite the fact that in the past five years, an increasing number of studies have focused on river plastic contamination. Data are still scarce and sampling methods need to be improved and harmonised (Dris et al., 2018; Eerkes-Medrano et al., 2015; Wagner et al., 2014). Moreover, there is a major need to set up networks for measuring microplastics in inland waters to monitor the evolution of their contamination over time and to set up databases at regional scales, in line with regional regulations, like the Water Framework Directive in Europe 

67 banks.

(although microplastics are not included as an indicator of good environmental status in its current version).

Only easy to implement methodologies can be considered. However, they have to be representative of the water bodies. The 200-year long experience in river monitoring suggests that fluctuations in usual water quality parameters occur at much larger time scales than those of sampling, and as a consequence, for instance, sampling $1 \mathrm{~L}$ of water is often enough to measure both dissolved and particulate water quality parameters. Such an experience is missing for microplastic contamination, in particular, for low concentration contamination, taking into account that the dynamics of such particles in the water column is up to now badly known. To the best of our knowledge, only two articles address small-scale temporal and spatial variability of microplastics found in rivers (Dris et al., 2018; Liedermann et al., 2018). Dris et al. (2018) analysed the temporal and spatial variability of fibre concentrations in the Seine and Marne Rivers (France), using a $80 \mu \mathrm{m}$ mesh net. They showed that the longer the net deployment time, the lower the variability between consecutive samples. They also assessed fibre distribution variability throughout the river cross-section and observed that concentrations are similar across the water column and tend to increase near the banks. Liedermann et al. (2018) studied microplastics distribution, using a $500 \mu \mathrm{m}$ mesh net, within the Danube River and also detected a slight tendency towards higher concentrations nearer the

On the basis of the sampling of 16 successive replicates and 3 sampling durations, in a river in Southwestern France, we investigate the microplastic concentration fluctuations and assess the corresponding uncertainties, and their variation with both the number of replicates and the time exposure. 


\section{Materials and Methods}

\section{Study site and sampling methodology}

This study was conducted on April $6^{\text {th }}, 2018$ between 11 am and 2 pm in the Gave de Pau River, downstream of the Pau city centre yet still within the conurbation (Southwestern France, lat.: $43.304828^{\circ}$, long.: $\left.-0.436492^{\circ}\right)$. At this location, the river is $87 \mathrm{~m}$ wide with a maximum depth of about $2 \mathrm{~m}$. The flow is torrential with an annual mean discharge of 69.1 $\mathrm{m}^{3} / \mathrm{s}$ (average over the period February 2000 - July 2018 at station Q5231010 - Gave de Pau at Artiguelouve - Pont de Lescar; Banque hydro database, 2018).

The river flow surface velocity was measured three times in a row before sampling using a flowmeter (Flow Probe FR211) and ranged from 1.0 to $1.2 \mathrm{~m} / \mathrm{s}$. The average value $(1.1 \mathrm{~m} / \mathrm{s})$ was used to estimate the volume of water being filtered by the net. The mean river flow at station Q5231010 was $75.8 \mathrm{~m}^{3} / \mathrm{s}$ (Banque hydro database, 2018).

Microplastic particles were sampled using a 330- $\mu \mathrm{m}$ mesh size net with a rectangular opening of $30 \mathrm{~cm}$ by $60 \mathrm{~cm}$. This net was attached to a bridge roughly 6 meters from the river's left bank. A second rope, fastened to the frame, was used to pull the net out of the water from the bank. Two buoys were assembled on top of the frame to hold it just over the water surface, and weights were used to keep it straight in the water column (Picture S1, Video S1).

A total of 16 samples were collected within a three-hour window. The maximum number of samples that can be collected in this time frame ranges from 15 to 20 depending on the net exposition time chosen. Beyond this time window, the hypothesis of steady state of the river flow and pollution could be wrong. It was decided to use low net exposition times to avoid clogging and reduce sampling and sample processing time. This is of high importance considering that the method should be operational for large scale monitoring. The various immersion times of the net chosen were $3 \mathrm{~min}$ (3 replicates), $5 \mathrm{~min}$ (10 replicates) and $7 \mathrm{~min}$ 
(3 replicates), corresponding to $35.6,59.4$ and $83.2 \mathrm{~m}^{3}$ of filtered water, respectively. The 5minute net exposition time $\left(59.4 \mathrm{~m}^{3}\right)$ was thought to be the best option. This time was therefore investigated further. Other values (i.e. 3 and 7 minutes, 35.6 and $83.2 \mathrm{~m}^{3}$ respectively) were also tested, although to a lower extent. Samples were stored in glass containers with metal lids away from sunlight and at room temperature.

\section{Microplastic extraction and identification}

The samples were run through sieves with mesh sizes of $5 \mathrm{~mm}$ and $0.3 \mathrm{~mm}$. The macroplastic fraction (> $5 \mathrm{~mm}$ ) was observed with the naked eye. The microplastic fraction, with a particle size lying between $0.3 \mathrm{~mm}$ and $5 \mathrm{~mm}$, was treated in order to remove organic matter (Masura et al., 2015; Hurley et al., 2018). $20 \mathrm{~mL}$ of aqueous $0.05 \mathrm{M} \mathrm{Fe}(\mathrm{II})$ solution and $20 \mathrm{~mL}$ of $30 \%$ hydrogen peroxide were added to a glass beaker containing the 0.3 to $5 \mathrm{~mm}$ fraction of the sample. The resulting mixture was then placed on a lab bench at room temperature for 5 minutes before being heated to $75^{\circ} \mathrm{C}$ and held at that temperature until gas bubbles could be observed. As the first bubbles cracked the surface, the beaker was removed from the hot plate to avoid a violent reaction. When the solution had cooled slightly, the beaker was returned to the hot plate and heated to $75^{\circ} \mathrm{C}$ for an additional 30 minutes. This operation was repeated four times per sample due to the high quantity of organic matter.

The plastic particles were then counted and classified under a binocular microscope (Leica EZ4) by colour (blue, red, transparent/white, black, green and other) and type (round, fragments, angular and other shapes) (MERI, 2015). The fibres were not considered in this study. The same operator handled all the samples. Tweezers were used to poke at individual items whenever doubts arose.

Given the size range target $(>330 \mu \mathrm{m})$, and as only fragments were considered, the risk of under or over estimation remains very low. In order to keep in mind the objective of a simple, 
rapid and efficient method, it was decided not to proceed to a chemical characterisation, as global methods based on Pyr-GC-MS are up to now high skilled and not quantitative, and spectroscopic techniques ( $\mu$ FTIR or $\mu$ Raman) are also high skilled and time consuming.

\section{Statistical analyses}

The number of plastic particles per sample was presented in terms of number of microplastics per cubic meter $\left(\mathrm{MPs} / \mathrm{m}^{3}\right)$. The median microplastic concentrations for the three volumes of filtered water, corresponding to the three exposure times, were compared using the nonparametrical Kruskal-Wallis test and the R software (R Core Team, 2018). Since the number of samples is small, non-parametric statistics, including medians and quantiles, are used.

Sampling uncertainties were assessed based on the 10 filtrations of $59.4 \mathrm{~m}^{3}$ (5 minutes). A resampling technique was applied to a number of samples ranging from 3 to 10 . The number of existing combinations varied from 560 (for 3 samples) to 8,008 (for 10 samples), with a maximum of 12,870 (for 8 samples). For each combination of samples, the mean medians and mean standard deviations of microplastic densities per cubic meter were computed. As the total number of combinations remains reasonable, all the combinations were tested. The standard errors of the means and confidence intervals were then computed using a $95 \%$ confidence level.

The delta of the standard errors of the means with respect to the median mean values has been plotted vs. the number of samples in order to determine how the number of samples influences the related uncertainties. 


\section{Results}

144 In total, 3,191 microplastics were found within the $950 \mathrm{~m}^{3}$ of filtered water. $11.88 \mathrm{~m}^{3}$ of water

145 were filtered per minute of exposure. Exposure times of 3, 5 and 7 minutes allowed filtering

$14635.6,59.4$ and $83.2 \mathrm{~m}^{3}$ of water, respectively. No macroplastic was caught in the net.

147 The microplastic concentrations varied between 2.64 and 4.24 MPs $/ \mathrm{m}^{3}$, with a median value 148 of $3.26 \mathrm{MPs} / \mathrm{m}^{3}$.

149 The shapes and colours of microplastic particles are presented in Table S1. The microplastic

150 shape and colour variability between samples is low (the standard error ranges from $3 \%$ to $8 \%$

151 for shape variability and from $0.3 \%$ to $9 \%$ for colour variability).

152

153

Influence of the net exposure time

154 The distribution of values recorded is shown in Figure 1.

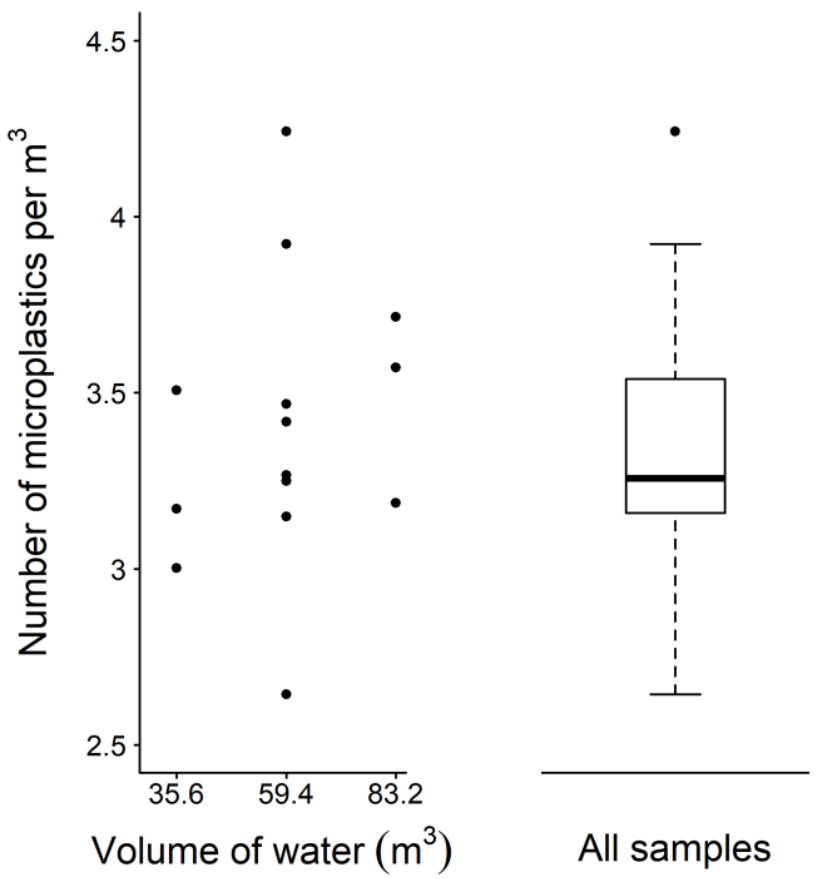

Figure 1: Plot of the microplastics concentration vs. volume of filtrated water, and boxplot of the microplastics concentration for all samples 
159 The microplastic concentration varies between 3.00 and $3.51 \mathrm{MPs} / \mathrm{m}^{3}, 2.64$ and $4.24 \mathrm{MPs} / \mathrm{m}^{3}$, 160 and 3.19 and $3.72 \mathrm{MPs} / \mathrm{m}^{3}$ for the three exposure times $(3,5$ and 7 minutes corresponding to $16135.6,59.4$ and $83.2 \mathrm{~m}^{3}$ ), respectively. Despite the exposure time, the concentrations remain 162 close although the 5-minute exposure covers a wider range of values.

163 A Kruskal-Wallis test does not highlight any statistical differences between microplastics concentration for each exposure time $(\alpha=0.05, \mathrm{p}=0.5)$. The median value of microplastic density per cubic meter for the 16 samples equals: $3.26 \pm 0.21 \mathrm{MPs} / \mathrm{m}^{3}$.

\section{Uncertainties}

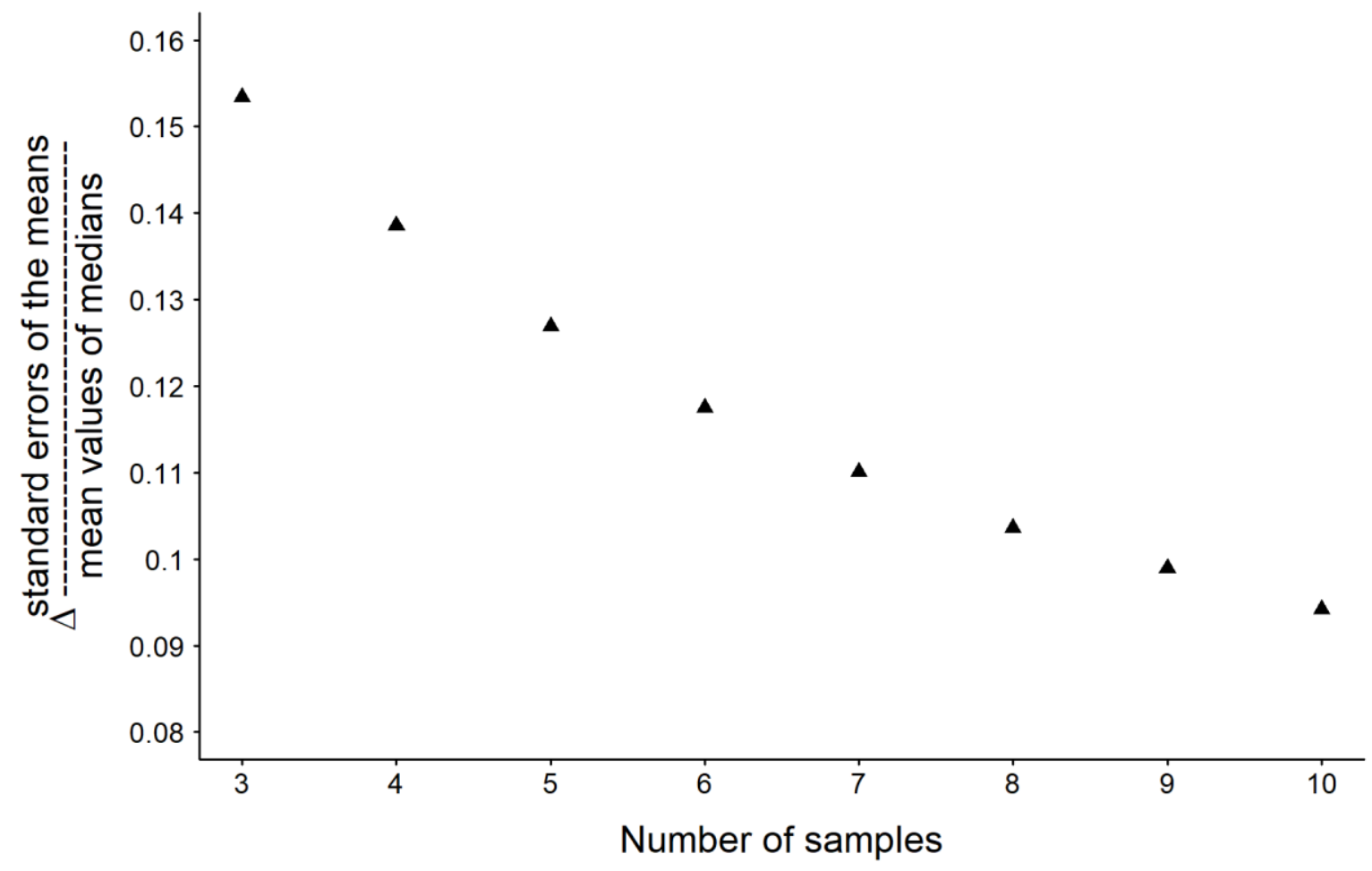

Figure 2: Delta of the standard errors of the means with respect to the median mean values vs. the number of samples extracted

Figure 2 presents the delta of the standard errors of the means with respect to the median mean values according to the number of samples extracted. This figure demonstrates that the 
higher the number of samples are, the lower the confidence interval. All values are given in Table S2.

Analyses conducted on the 10 filtrations of $59.4 \mathrm{~m}^{3}$ (5 minutes) have shown that for triplicates, the mean confidence interval for the 560 combinations reaches $15 \%$ of the median value, while the maximum confidence interval for the 560 combinations reaches $40 \%$ of the median value. The confidence interval for all 10 samples is the lowest, i.e. reaching $9 \%$ of the median value (95\% confidence level). Values for mean and maximum confidence intervals for each combination of samples are given in Table S2.

\section{Discussion and conclusion}

The median concentration of microplastics in the Gave de Pau River $\left(3.26 \pm 0.21 \mathrm{MPs} / \mathrm{m}^{3}\right)$ was ten times higher than concentrations measured in the Danube River between Vienna and Bratislava (0.32 MPs/m³; Lechner et al., 2014; exposition time and volume of water filtered not mentioned) and in the Seine River downstream of the heavily-populated Paris Basin (0.35 MPs $/ \mathrm{m}^{3}$, mesh size: $330 \mu \mathrm{m}$, net towed behind a motor boat for 15 minutes at about $2 \mathrm{~m} / \mathrm{s}$ for a volume of filtered water ranging from 182 to $200 \mathrm{~m}^{3}$, Dris et al., 2015). Contrary to Dris et al. (2018), who observed a decrease in variability between samples for longer exposure times, our results do not present such a correlation. A comparison with other studies proves to be difficult due to the significant differences in methods, extraction protocols and units (Li et al., 2018). The work presented in this study is based on 16 samples, all extracted on the same day, at the same location and within a time window for which the river flow and pollution can be considered in a steady state. This value does not therefore reflect temporal variability in microplastics concentration (van Emmerik et al., 2018) and hence does not reflect the mean annual load of the river either. 
The large quantity of microplastics in our samples can be explained by the fact that two former landfills, located near the riverbanks upstream of our site, were swept by the river during several flooding events, the most recent occurring in February 2018. No chemical characterisation was conducted. Visual identification of microplastics can sometimes lead to substantial errors; however, given the size range target $(>330 \mu \mathrm{m})$, and because only fragments were considered, the risk of under or over estimation remains very low. Moreover, this bias is similar for all samples as the same operator handled all manipulations and it is therefore possible to compare them. Microplastic concentrations for the three net exposition times could not be shown to be statistically different. This result should be handled with caution due to the low number in some groups of samples. This point in mind, it seems that the filtration of approx. $35 \mathrm{~m}^{3}$ of water is appropriate for future samplings under similar conditions (similar flow condition and similar degree of microplastic contamination of the river). This lower volume of water could reduce the time devoted to sampling, sample treatment and identification. To verify that the conditions are similar to the ones describe is this study, researchers are urged to use this method to investigate whether those results apply to their rivers or not before starting a monitoring and setting up a monitoring station at a specific river location. The number of samples taken for each volume of filtrated water should ideally be the same to ensure statistics robustness. When choosing the different volumes of water to be filtered as a first test, mind that a long exposure of the net might allow the catch of rare particles, the setback being that the net could clog rapidly in case of high concentration of suspended matter.

The 10 samples of $59.4 \mathrm{~m}^{3}$ (5 minutes) extracted gave us the opportunity to study the correlation between the number of samples collected and associated uncertainties. For triplicates, the mean confidence interval reached $15 \%$ of the median value. The confidence interval decreased quickly the higher the number of samples: it can drop to $9 \%$ of the median 
value for all 10 samples. Thus, collecting triplicates seems to be a reasonable optimum that combines an acceptable error percentage and time efficiency. These results might depend on the microplastic load of the river, therefore prompting the need to conduct similar analyses on other rivers. The order of magnitude of uncertainties reported in this paper can potentially be affected by: i) time exposure, ii) river hydrodynamic conditions (low vs. high water levels), and iii) the amount of microplastics sampled. As such, similar work must be performed under other conditions.

This study has reported, for the very first time, uncertainties related to microplastic sampling in rivers. The median concentration of microplastics in the Gave de Pau River recorded in this study $\left(3.26 \pm 0.21 \mathrm{MPs} / \mathrm{m}^{3}\right)$ is day-specific and do not allow for any extrapolation. Under similar conditions, a 3-minute exposure time for the net (filtration of approx. $35 \mathrm{~m}^{3}$ ) and the collection of triplicates seem to offer a reasonable optimum, by virtue of combining an acceptable error percentage and time efficiency. Even if these results have to be confirmed by increasing the number of samples per time exposure, this paper share a methodology that helps design better microplastics studies. These results will help to set up long term monitoring, determine microplastic fluxes and highlight the spatial difference between sites.

\section{Acknowledgments}

This study was funded by the French Ministry of Ecology and Solidary transition and the Direction Inter-Régionale de la Mer Sud-Atlantique. The authors would also like to thank Lauren Meshako from the Surfrider Foundation Europe and Robert Sachs for proofreading this article. 
The authors hereby declare the absence of any conflicts of interest.

\section{References}

Banque Hydro. Available online: http://www.hydro.eaufrance.fr/ (accessed on 9 August 2018).

251

252

Dris, R., 2016. First assessment of sources and fate of macro-and micro-plastics in urban hydrosystems: Case of Paris megacity (Doctoral dissertation, UPE, Université Paris-Est).

Dris, R., Gasperi, J., Rocher, V., Saad, M., Renault, N., Tassin, B., 2015. Microplastic contamination in an urban area: a case study in Greater Paris. Environmental Chemistry 12(5), 592-599.

Dris, R., Gasperi, J., Rocher, V., Tassin, B., 2018. Synthetic and non-synthetic anthropogenic fibers in a river under the impact of Paris Megacity: sampling methodological aspects and flux estimations. Science of the Total Environment 618, 157-164.

Eerkes-Medrano, D., Thompson, R. C., Aldridge, D. C., 2015. Microplastics in freshwater systems: a review of the emerging threats, identification of knowledge gaps and prioritisation of research needs. Water research 75, 63-82.

Hurley, R. R., Lusher, A. L., Olsen, M., Nizzetto, L., 2018. Validation of a method for extracting microplastics from complex, Organic-Rich, Environmental Matrices. Environmental science \& technology 52(13), 7409-7417.

Liedermann, M., Gmeiner, P., Pessenlehner, S., Haimann, M., Hohenblum, P., Habersack, H., 2018. A Methodology for Measuring Microplastic Transport in Large or Medium Rivers. Water 10(4), 414.

Li, J., Liu, H., Chen, J. P., 2018. Microplastics in freshwater systems: A review on occurrence, environmental effects, and methods for microplastics detection. Water research 137, 362-374.

Li, W. C., Tse, H. F., FOK, L., 2016. Plastic waste in the marine environment: A review of sources, occurrence and effects. Science of the Total Environment, 566, 333-349. 
Lechner, A., Keckeis, H., Lumesberger-Loisl, F., Zens, B., Krusch, R., Tritthart, M., Glas, M.,

271 Schludermann, E., 2014. The Danube so colourful: a potpourri of plastic litter outnumbers fish larvae

272 in Europe's second largest river. Environmental Pollution 188, 177-181.

273 Masura, J., Baker, J. E., Foster, G. D., Arthur, C., Herring, C., 2015. Laboratory methods for the

274 analysis of microplastics in the marine environment: recommendations for quantifying synthetic

275 particles in waters and sediments. NOAA Technical Memorandum NOS-OR\&R-48.

276 MERI (Marine and Environmental Research Institute), 2015. Guide to microplastic identification.

277 Available from:

278 http://www.ccb.se/documents/Postkod2017/Mtg050317/Guide\%20to\%20Microplastic\%20ldentifica 279 tion_MERI.pdf.

280 R Core Team, 2018. R: A language and environment for statistical computing. R Foundation for 281 Statistical Computing, Vienna, Austria. URL https://www.R-project.org/.

282 van Emmerik, T., Kieu-Le, T.C., Loozen, M., van Oeveren, K., Strady, E., Bui, X.T., Egger, M., Gasperi, J., 283 Lebreton, L., Nguyen, P.D., Schwarz, A., 2018. A Methodology to Characterize Riverine Macroplastic 284 Emission into the Ocean. Frontiers in Marine Science 5 (372).

285 Wagner, M., Scherer, C., Alvarez-Muñoz, D., Brennholt, N., Bourrain, X., Buchinger, S., Fries, E., 286 Grosbois, C., Klasmeier, J., Marti, T., Rodriguez-Mozaz, S., Urbatzka, R., Vethaak, A. D., Winther287 Nielsen, M., Reifferscheid, G., 2014. Microplastics in freshwater ecosystems: what we know and what we need to know. Environmental Sciences Europe 26, 12. 